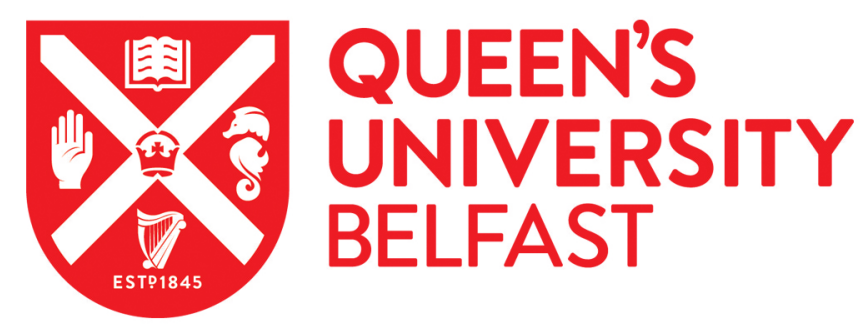

\title{
An assessment of wind and wave climate as potential sources of renewable energy in the nearshore Shenzhen coastal zone of the South China Sea
}

Chen, X., Wang, K., Zhang, Z., Zeng, Y., Zhang, Y., \& O'Driscoll, K. (2017). An assessment of wind and wave climate as potential sources of renewable energy in the nearshore Shenzhen coastal zone of the South China Sea. Energy, 134, 789-801. https://doi.org/10.1016/j.energy.2017.06.043

Published in:

Energy

Document Version:

Peer reviewed version

Queen's University Belfast - Research Portal:

Link to publication record in Queen's University Belfast Research Portal

\author{
Publisher rights \\ Copyright 2017 Elsevier. \\ This manuscript is distributed under a Creative Commons Attribution-NonCommercial-NoDerivs License \\ (https://creativecommons.org/licenses/by-nc-nd/4.0/), which permits distribution and reproduction for non-commercial purposes, provided the \\ author and source are cited.
}

\section{General rights}

Copyright for the publications made accessible via the Queen's University Belfast Research Portal is retained by the author(s) and / or other copyright owners and it is a condition of accessing these publications that users recognise and abide by the legal requirements associated with these rights.

Take down policy

The Research Portal is Queen's institutional repository that provides access to Queen's research output. Every effort has been made to ensure that content in the Research Portal does not infringe any person's rights, or applicable UK laws. If you discover content in the Research Portal that you believe breaches copyright or violates any law, please contact openaccess@qub.ac.uk. 


\title{
An assessment of wind and wave climate as potential sources of renewable energy in the nearshore Shenzhen coastal zone of the South China Sea
}

\author{
Xinping Chen ${ }^{\mathrm{a}}$, Kaimin Wang ${ }^{\mathrm{b}}$, Zenghai Zhang ${ }^{\mathrm{c}}$, Yindong Zeng ${ }^{\mathrm{d}}$, Yao \\ Zhang $^{\mathrm{a}, *}$, Kieran O'Driscoll ${ }^{\mathrm{e}}$ \\ ${ }^{a}$ National Marine Hazard Mitigation Service of State Oceanic Administration, Beijing \\ 100194, China. \\ ${ }^{b}$ Shenzhen Marine Monitoring Forecasting Center, Shenzhen 518067, China. \\ ${ }^{c}$ National Meteorological Center of China Meteorological Administration, Beijing 100081, \\ China. \\ ${ }^{d}$ Marine Forecasting Center of Fujian Province, Fuzhou 350003, China. \\ ${ }^{e}$ School of Natural and Built Environment, Queen's University Belfast, Belfast, Northern \\ Ireland, UK.
}

\begin{abstract}
In this study, nearshore wind and wave climates and their potential as renewable energy sources are evaluated by means of buoy observational data for the Shenzhen coastal region. Six buoys were originally deployed in the region by the city local government of China in 2014, and are located in different areas of the study region, including Dapeng Bay, Daya Bay, Shenzhen Bay. The waters in these areas are relatively shallow, ranging in depth between about 3-22 m. The results show that during 2014-2016, annual mean wind speeds (at $2.5 \mathrm{~m}$ above the sea surface) in the region varied between 3.1-4.1 $\mathrm{m} \mathrm{s}^{-1}$, leading to wind powers between $37-94 \mathrm{~W} \mathrm{~m}^{-2}$; significant wave
\end{abstract}

\footnotetext{
${ }^{*}$ Corresponding author.

Email addresses: xinp.chen@foxmail.com (Xinping Chen), yaozhang_zhang@126.com (Yao Zhang)
} 
heights were mostly less than $1 \mathrm{~m}$, while wave energy periods were mostly in the range $3-7 \mathrm{~s}$. As a result, wave power was mostly less than $1.0 \mathrm{~kW} \mathrm{~m}^{-1}$. It is concluded that the potential of wave energy as a renewable resource at the buoy locations was very small. This may be due to the fact that, first, water depth is very shallow, and, secondly, the buoys are located in bays where the sea is somewhat semi-enclosed, all of which are not favourable for the development of wind waves.

Keywords: Wave climate, Wave energy, Shenzhen, Wind climate, Wind energy, the South China Sea

\section{Introduction}

Energy has become one of the hottest words in China. On the one hand,

3 the demand for energy in China is rapidly increasing, since China has become

the largest energy consumer and producer in the world (US Energy Information Administration, EIA; http://www.eia.gov/), whereas on the other, energy is closely associated with the environment. For example, coal and oil consumption in the country has resulted in very seriously bad air pollution impacts and environmental problems, which have been reported on in countless situations. Air pollution and smog in China have become one of the most contentious issue for the international media. Hundreds of millions of people in the world's most populous country are suffering the effects of this pollution, which is putting a lot of pressure on environmental and public health conditions in China. To mitigate these problems, China has to accelerate the adjustment of energy structure and to increase the share of clean sources in its energy mix. According to China's Action Plan for the Prevention and 
Control of Air Pollution [1], China desires to reduce coal consumption to less than $65 \%$ in terms of total energy consumption by 2017 .

China has a very long coastline, possessing rich ocean resources, which attach great importance to marine development and exploitation of renewable energy. As important renewable types, ocean wind and wave energy not only provide China with energy sources, but also resources with which to address and relieve the challenge of energy demands with resepect to the environment , while implementing a sustained development strategy. As [2] mentioned, renewables can also provide tools to address many pressing needs, including improving energy security, reducing human health problems, and mitigating against greenhouse gas emissions.

In recent times (decades), previous researchers have made great contributions toward the assessment of wind/wave energy potential for various seas in many regions and countries, based on the analysis of wind/wave data collected from buoys, remote sensing, numerical hindcasts, and combinations of these sources. Included among these are the following studies: for the UK [3, 4], Portugal [5-7], Sweden [8], Belgium [9], Spain [10-13], Ireland [14, 15], Europe [16], the North Sea [9], the Baltic Sea [17, 18], the Red Sea [19], the Caribbean [20], Australia [21, 22], Canada [23], Iran [24], India [25-29], Korea [30], Singapore [31], Chile [32], the Hawaiian islands [33, 34], Southern New England [35], California [36, 37], the Atlantic coast of the southeastern USA [36, 38], the US Pacific Northwest [39], as well as for the global ocean (e.g., [40-44]). In addition, wave/wind energy resource assessment has also been conducted for China [e.g., 45-54], and also including for Hongkong [55-58].

The region of interest in the present study is near the coast of Shenzhen, 
located at the northern extreme of the South China Sea. Shenzhen shares a border with Hong Kong to the south, is $160 \mathrm{~km}$ south of the provincial capital of Guangzhou, and $70 \mathrm{~km}$ south of the industrial city of Dongguan. To the west, the resort city of Zhuhai is a $60 \mathrm{~km}$ away, (see Fig. 1). Shenzhen was the earliest of the five special economic zones in China, originally established in 1979, and was given the right of provincial-level economic administration. Since then, it has been one of the fastest growing cities in the world, and eventually became one of the largest cities in the Pearl River Delta region from the one-time small fishing village, and one of the economic powerhouses of China, as well as of the largest manufacturing bases in the world. As a result of this tremenduous economic growth, the demand for energy is no doubt correspondingly rapidly increasing. The first nuclear power plant in China was built in the coast of Daya Bay (see Fig. 1), a coastal region of Shenzhen. However, relative to the economic growth, the marine development of Shenzhen has fallen far behind. It wasn't until 2014 that the city local government put buoys in the surrounding waters to observe and monitor the atmospheric and hydrodynamic climate of the region, and for use in marine and meteorology environmental studies and forecasting, and so on. The locations of the buoys have been shown to be reasonably representative of the hydrodynamic climate of different areas in this region, in a limited expenditure, and, from these, 6 buoy locations were selected (see section 2 for details). This was a great progression and good start for marine observations and monitoring for this region.

By means of data collected from six buoys located in the nearshore Shenzhen zone, this study aims to evaluate wind and wave climate for the region, 
in terms of wind speed and direction, wave height, wave period and wave direction. The potential of wind and wave energy as resources is assessed based on buoy observations for the period 2014-2016. Location of the area of interest and accumulated data at each of the six buoys, and also bathymetry of the region are described in detail in section 2 , where the methods for estimating wind and wave power are also presented. Wind and wave resource variability in the region are investigated and discussed in section 3. Finally, conclusions are presented in section 4 .

\section{Data and methods}

\subsection{Study area and buoy data}

The region of wind and wave energy resource under investigation extends from $22.0^{\circ} \mathrm{N}-23.0^{\circ} \mathrm{N}$ and $113.5^{\circ} \mathrm{E}-114.5^{\circ} \mathrm{E}$ (Fig. 1), and includes the entire nearshore region of Shenzhen adjacent to Hong Kong. Six buoys, acquired from Shenzhen Marine Montoring Forecasting Center, are available in the study region, and their locations and corresponding mean water depths are listed in Table 1. Data from these buoys represent the wind and wave climate for different areas of the Shenzhen coastal region, mainly to monitor atmospheric and hydrodynamic changes in this region and also to be used for marine environmental investigating, forecasting, etc. The study area consists of the waters extending from Shenzhen Bay in the northwest, southward and eastward containing waters surrounding Hong Kong to Dapeng Bay, east of Hong Kong and further east to include Daya Bay. The six buoys are located very close to shore in very shallow water across the three bays: B1 is located in the northwest end of Dapeng Bay in water depth of about $11 \mathrm{~m}$; B2 is also 
located in Dapeng Bay, close to the western side of Dapeng Peninsula; B3 is located in Aozaixia Bay in inner Daya Bay in water depth of only about $3 \mathrm{~m}$; B5 is situated in southern Daya Bay (water depth: $12 \mathrm{~m}$ ); B4 is located in the relatively open area off the tip of Dapeng peninsula in water depth of about $22 \mathrm{~m}$; and B6 is located in inner Shenzhen Bay, in a relatively narrow and closed area with water depth only $3 \mathrm{~m}$.

The six buoys have been in operation since April 2014. Wave data were provided hourly, consisting of wave parameters, including wave height, period and direction. However, some wave data were not recorded over a span of several days, and data gaps for each buoy can be inferred from Fig. 7. Significant wave height $\left(H_{s}\right)$, which is identical to the average of the highest one-third of all wave heights recorded during each wave acquisition, is utilized and analyzed for wave energy assessment in this study, while the measured wave period acquired from buoy measurements refers to mean wave period, $T_{m}$. However, only buoys $\mathrm{B} 1-\mathrm{B} 4$ and $\mathrm{B} 6$ provided records of wind data (at $2.5 \mathrm{~m}$ above sea surface), including wind speed and direction at quarterhourly intervals, except for B4 (mainly half-hourly). Wind direction at B6 was also missed.

\subsection{Analytical methods and approach}

Wind power is defined as the power per unit section perpendicular to wind flow, and is computed in this study by the following equation [52]:

$$
W=\frac{1}{2} \rho_{a} V^{3}
$$

in which $W$ is wind power in units of $\mathrm{W} \mathrm{m}^{-2}, V$ is wind speed (unit: $\mathrm{m} \mathrm{s}^{-1}$ ), and $\rho_{a}$ is air density taken as $1.292 \mathrm{~kg} \mathrm{~m}^{-3}$ and corresponding to that close 
to the sea surface in the region of interest in this study.

It was noticed that, for wave power calculations and assessments, the widely used wave period is the so-called wave energy period, $T_{e}$, instead of $T_{m} . T_{e}$ can be defined as $T_{e} \equiv T_{-10}=\frac{m_{-1}}{m_{0}}$, in which $m_{n}$ is the $n^{\text {th }}$ moment of spectral density, i.e., $m_{n}=\int_{0}^{2 \pi} \int_{0}^{\infty} f^{n} S(f, \theta) d f d \theta$, and here $f$ is the wave frequency, $\theta$ is the wave direction, and $S(f, \theta)$ is the $2 \mathrm{D}$ wave spectrum. In general, the observed wave period measured by buoys for real sea states is rarely specified by $T_{e}$, but is specified in terms of the mean wave period $T_{m}$, or in terms of the peak period $T_{p}$. $T_{e}$ is often estimated by means of its relation to other observational wave periods, such as $T_{m}$ and $T_{p}$, when the spectral density is unknown [40]. Therefore, the relationship between $T_{e}$ and $T_{p}$ can be estimated by the formula $T_{e}=\alpha T_{p}$, in which $\alpha$ depends on the shape of the wave spectrum used to define the sea state. The relationship between $T_{p}$ and $T_{e}$ used in this study is computed by a conservative approximation that $T_{e}=0.9 T_{p}$, according to the study of [40]. This relationship has been widely adopted in assessing the wave energy resource such as off the coast of Canada [23], in the North Sea [9], and for the global ocean [40] as well as for the offshore wave power in the East China Sea [54].

Based on the study of $[8,10-12,28,41,54]$, the wave power, $P$, known as wave energy flux as well, is calculated by the following expression

$$
P=\frac{\rho_{w} g^{2}}{64 \pi} H_{s}^{2} T_{e}
$$

where $\rho_{w}$ represents sea water density taken as $1025 \mathrm{~kg} \mathrm{~m}^{-3}$, the average sea water density in the study area. Since $T_{p}$ was not provided in the buoy records acquired in this study, $T_{m}$ was used to estimate the wave power in the region of interest. Following the study of [54, 59], the relationship between 
$T_{m}$ and $T_{p}$ is adopted as $T_{p}=1.2 T_{m}$, and as a result, $T_{e}$ investigated in the present study is computed by means of $T_{m}$ as $T_{p}=0.9 \times 1.2 T_{m}=1.08 T_{m}$.

\section{Results and Discussion}

\subsection{Wind climate and assessment of wind energy potential}

To assess the wind climate in the Shenzhen coastal region, the time series of wind speeds based on the buoy measurement data (B1-B4 and B6) for the period 2014-2016 is plotted by Fig. 2. It can be observed that wind speeds in the study area were mostly less than $8 \mathrm{~ms}^{-1}$ for the 5 buoys except B4 buoy, where the wind speed was generally less than $10 \mathrm{~m} \mathrm{~s}^{-1}$; relatively high wind speeds of greater than $15 \mathrm{~m} \mathrm{~s}^{-1}$ occurred occasionally. Based on Eq. 2, Fig. 3 displays the calculated wind power for the 5 buoys. It shows that the wind power for the 5 buoys (except B4) was mostly less than $300 \mathrm{~W} \mathrm{~m}^{-2}$, while B4 shows relatively larger wind speeds, with values mostly smaller than $500 \mathrm{~W} \mathrm{~m}^{-2}$. Large wind power values of more than $3500 \mathrm{~W} \mathrm{~m}^{-2}$ can occasionally be found in the observed time.

The fundamental characteristics of wind energy resources, in terms of the annual mean wind speed with its standard deviation (( $V_{\text {mean }} \pm$ std.dev. $)$, maximum wind speed $\left(V_{\max }\right)$, annual mean and maximum wind power (i.e., $W_{\text {mean }}$ and $\left.W_{\text {max }}\right)$, is summarized in Table 1 . In Dapeng bay, represented by buoys B1 and B2, the annual mean wind speed during 2014-2016 was $3.1 \mathrm{~m} \mathrm{~s}^{-1}$, and in Daya Bay, represented by B3, $V_{\text {mean }}$ was $3.4 \mathrm{~m} \mathrm{~s}^{-1}$; similarly, in Shenzhen bay, as B6 shows, $V_{\text {mean }}$ was $3.6 \mathrm{~m} \mathrm{~s}^{-1}$; relatively stronger wind speed was found at B4, with mean wind speed of $4.1 \mathrm{~m} \mathrm{~s}^{-1}$. In accordance with the mean wind speed, the annual mean wind power, $W_{\text {mean }}$, 
at $\mathrm{B} 1$ and $\mathrm{B} 2$ was, respectively, $58 \mathrm{~W} \mathrm{~m}^{-2}$ and $37 \mathrm{~W} \mathrm{~m}^{-2}$, and $W_{\text {mean }}$ was around $50 \mathrm{~W} \mathrm{~m}^{-2}$ in Daya bay and Shenzhen bay, highest $W_{\text {mean }}$ among the buoys was found at $\mathrm{B} 4$ with value of $94 \mathrm{~W} \mathrm{~m}^{-2}$. $V_{\text {mean }}$ averaged at the buoys was about $3.5 \mathrm{~m} \mathrm{~s}^{-1}$, leading to an average $W_{\text {mean }}$ of around $58 \mathrm{~W} \mathrm{~m}^{-2}$ for 2014-2016.

For the period 2014-2016, maximum wind speed, $V_{\max }$, at B1, B2, and B4 was, respectively, $17.5 \mathrm{~m} \mathrm{~s}^{-1}, 17.6 \mathrm{~m} \mathrm{~s}^{-1}, 17.1 \mathrm{~m} \mathrm{~s}^{-1}$, leading to wind power of more than $3000 \mathrm{~W} \mathrm{~m}^{-2}$, while $V_{\max }$ was relatively smaller at B3 and B6, with values of $15.66 \mathrm{~m} \mathrm{~s}^{-1}$ and $15.7 \mathrm{~m} \mathrm{~s}^{-1}$, respectively, giving a corresponding $W_{\text {max }}$ of over $2300 \mathrm{~W} \mathrm{~m}^{-2}$.

It is noted that the study region is influenced by tropical cyclones (TCs; normally called typhoons in China) relatively frequently, and they have been reported many times. Therefore, the variance of maximum wind speeds can be quite large for different time periods. Maximum wind speed depends greatly on the extent and degree of the TC effects. For example, for the period 2014-2016, 3 TCs passed through the study region that had much influence it, see Fig. 4. The periods of these TCs are plotted in Fig. 2, and it is observed that wind speeds in these time were relatively high. TCS are normally classified into different categories. In China, in accordance with the World Meteorological Organization's recommendation, the classification is divided into 6 categories by the classification of TCs standardization of China (GB/T19201-2006 [60]), in terms of wind speed averaged over a period of 10 minutes near the center of the TC. The six classifications are as follows: Tropical Depression (TD; $10.8-17.1 \mathrm{~m} \mathrm{~s}^{-1}$ ); Tropical Storm (TS; 17.2-24.4 $\mathrm{m} \mathrm{s}^{-1}$ ); Severe Tropical Storm (STS; 24.5-32.6 $\mathrm{m} \mathrm{s}^{-1}$ ); Typhoon 
(TY; 32.7-41.4 $\mathrm{m} \mathrm{s}^{-1}$ ); Severe Typhoon (STY; $41.5-50.9 \mathrm{~m} \mathrm{~s}^{-1}$ ); and Super Typhoon (SuperTY; $\geqslant 51.0 \mathrm{~m} \mathrm{~s}^{-1}$ ). Fig. 4 shows that TCs Nida (No. 1604) and Haima (No. 1622) were in the classification of STY when they landed (around Aug. 2 and Oct. 21 in 2016, respectively), and correspondingly, the wind speeds could reach up to $15 \mathrm{~m} \mathrm{~s}^{-1}$ at B1, B2 and B4 locations, while they were relatively small (about $10 \mathrm{~m} \mathrm{~s}^{-1}$ ) at locations B3 and B6. Linfa (No. 1510) was much weaker when it came to the Shenzhen region, and its influence on wind speed was much less. The other 3 TCs displayed in Fig. 4 were relatively far from the study region, but their influence is still seen: wind speed at the 4 buoys were all relatively large with values reaching $15 \mathrm{~m} \mathrm{~s}^{-1}$, in the influence of the Kalmaegi (No. 1415); the other two TCs were also evident for the wind speeds in the study area.

The seasonal and monthly mean wind speed variations at the wind buoys in the study area are presented by Fig. 5. For the present study, the four boreal seasons are winter (December-February), spring (March-May), summer (June-August), and Autumn (September-November). The monthly wind speeds over the period 2014-2016 varied from about $2-6 \mathrm{~m} \mathrm{~s}^{-1}$, with different variability found at each of the buoys. Highest monthly mean wind speeds occurred at station B4, with values of about $5.6 \mathrm{~m} \mathrm{~s}^{-1}$ in November 2015 , followed by station B1 $\left(5.2 \mathrm{~m} \mathrm{~s}^{-1}\right.$ in December 2014). However, at location B6 in Shenzhen Bay, the largest monthly wind speed was not found in winter, but in June $2015\left(4.3 \mathrm{~m} \mathrm{~s}^{-1}\right)$, followed by June $2016\left(4.2 \mathrm{~m} \mathrm{~s}^{-1}\right)$, while the smallest monthly value was reported in October 2016.

Corresponding to wind speeds, monthly mean wind powers at the 5 buoy locations varied from $20 \mathrm{~W} \mathrm{~m}^{-2}$ to $200 \mathrm{~W} \mathrm{~m}^{-2}$ : relatively large wind powers 
can be found in autumn and winter months at B1 and B4; while at B6 wind powers in June and July were larger than those in winter months.

Fig. 5 also shows that the variation of monthly mean wind speeds and powers within a year was largest at B1, followed by B4, and was smallest at B3. Furthermore, no coincident seasonal variability was found in the winds and the wind powers at any of the buoy locations for 2014-2016. Of these, stations B1 and B4 show similar seasonality: winds and wind powers were relatively large in autumn and winter, and were smaller in the spring and summer months; however, B2 and B3 locations did not show evident seasonality. Note that the data in some months for B2 was lacking, which may influence the accuracy of its seasonality. On the contrary, B6 location shows opposite seasonality when compared with B1 and B4 during the study period: winds and wind powers were relatively large in spring and summer, and were smaller in autumn and winter months.

Besides wind speed, wind direction is another important parameter in wind energy assessment. For the data collected at the 6 buoys, only that at buoys B1-B4 include wind direction data. Wind direction and wind speed for different seasons at the 4 buoys is presented in terms of a wind rose figure, Fig. 6. It can be seen that variability in wind direction is different for the 4 buoy locations. At location B1, in winter, easterly winds prevailed (about $31 \%$ ), followed by winds directed from the ESE (about 28\%), and occasionally from the ENE and N (about 7\%), whereas westerly winds are least frequent (less than 5\%); in spring, prevailing direction was from the II quadrant, i.e., from $\mathrm{E}$ to $\mathrm{S}$, with least occurrence also from the west; in autumn and winter, winds were mostly southerly, followed by SSE and SSW directions, 
respectively, and winds from land, i.e., from the IV and I quadrants, provided the smallest contribution to the wind energy at B1. For B2, the prevailing wind direction was easterly in all seasons (over 45\%), followed by ENE, and lowest occurrence occurred from SE to NW. At location B3 in Daya Bay, for all seasons the largest contribution to wind energy resources was provided by southerly winds, and SSE and SSW winds also provided considerable contributions. At the B4 location, the prevailing wind direction varied for all seasons, with almost all occurrence from each direction being less than 15\%: in winter, most winds were from the the I quadrant followed by the II quadrant; W (about 16\%) prevailed in spring, followed by WSW (14\%) and WNW (13\%); southerly winds prevailed in autumn, and winds from E to $\mathrm{W}$ accounted for more than $75 \%$ of occurrence; in autumn, most winds were from the III quadrant.

The occurrence of wind speed at the 4 buoy locations during 2014-2016 can also be observed from Fig. 6. For B1, the occurrence of wind with speed less than $5 \mathrm{~m} \mathrm{~s}^{-1}$ was, respectively, about $85 \%, 88 \%, 90 \%$, and $70 \%$ in the 4 seasons (winter, spring, summer and autumn); relatively large wind speeds of over $8 \mathrm{~m} \mathrm{~s}^{-1}$ are mostly found in autumn (about 10\%), followed by winter (about $3 \%$ ). For B2, around $86 \%$ of wind speed was less than $5 \mathrm{~m} \mathrm{~s}^{-1}$ in all seasons except spring, when it was around $80 \%$; the occurrence of wind speed greater than $8 \mathrm{~m} \mathrm{~s}^{-1}$ was always less than $1 \%$ of the time in all seasons. At B3 wind speed was less than $5 \mathrm{~m} \mathrm{~s}^{-1} 80 \%$ of the time, while wind speed greater than $8 \mathrm{~ms}^{-1}$ also occurred relatively rarely (less than $2 \%$ for all seasons). Among the 4 buoys wind speed was greatest at B4, where wind speeds were over $5 \mathrm{~m} \mathrm{~s}^{-1}$ in winter and autumn about $45 \%$ of the time, and $20 \%$ of the 
time in summer and spring; the occurrence of wind speed over $8 \mathrm{~m} \mathrm{~s}^{-1}$ was, respectively, about $10 \%, 3.6 \%, 3.8 \%$, and $1.5 \%$ in winter, spring, summer and autumn.

\subsection{Wave climate and assessment of wave energy potential}

In this section, wave state in terms of observed wave height and calculated wave energy period is analyzed. Time series of significant wave height, $H_{s}$, and wave energy period, $T_{e}$, at the six buoys considered in this study are presented in Fig. 7. It can be seen from this figure that $H_{s}$ is relatively low for most of the period 2014-2016. At the 6 buoy stations, $H_{s}$ was less than $1 \mathrm{~m}$, most of the time, and was even less than $0.5 \mathrm{~m}$ at buoy stations B2, B3, and B6. It is not surprising that $H_{s}$ is small in this region, since, first of all, water depth is very small, and, secondly, the buoys are located in bays that are somewhat semi-closed, all of which are not favorable for the development of wind waves. Among these six buoys, $H_{s}$ at B4 was relatively higher than that at the others, which is to be expected since the water is deepest here while being closer to the open South China Sea. Relatively higher values exceeding $2 \mathrm{~m}$ are found only in some rare cases due to relatively strong winds caused by tropical cyclones passing through the region, see discussion above. For the period 2014-2016, no extreme waves (e.g., $H_{s}>10 \mathrm{~m}$ ) were observed, even during periods of influence from tropical cyclones passing through.

$T_{e}$ at the buoys is also presented in Fig. 7. In inner Dapeng Bay, represented by $\mathrm{B} 1$ and $\mathrm{B} 2, T_{e}$ mostly varies between $3 \mathrm{~s}$ and $7 \mathrm{~s}$, with occasional values of more than $10 \mathrm{~s}$. Similarly, at B5, in Daya bay, $T_{e}$ was also mostly in the range of $3-7 \mathrm{~s}$. Relatively higher $T_{e}$ was found at $\mathrm{B} 4$, with most values between 4-7s. In Aozaixia Bay (inner Daya Bay) represented by B3, $T_{e}$ was 
relatively small and mostly in the range $3-5 \mathrm{~s}$, Similar values of $T_{e}$ are found in Shenzhen Bay represented by B6. Moreover, $T_{e}$ values greater than $10 \mathrm{~s}$ occasionally occurred at the 6 buoys, mostly due to the influence of tropical cyclones.

Based on $H_{s}$ and $T_{e}$, the wave power, $P$, was estimated at the 6 buoy stations, Fig. 8. From comparison with time series of $H_{s}$ shown in Fig. 7, the temporal variations of $P$ and $H_{s}$ were basically coherent, at both hourly, daily and monthly time scales. This can be explained from the relation of $P$ and $H_{s}$, since $P$ is proportional to the square of $H_{s}$. For the period 2014-2016, $P$ was mostly confined to the range of $10^{2}$ to $10^{3} \mathrm{~W} \mathrm{~m}^{-1}$ at $\mathrm{B} 1, \mathrm{~B} 4$ and $\mathrm{B} 5$, while at B2, B3 and B6 wave power was considerably less, with values mostly less than $100 \mathrm{~W} \mathrm{~m}^{-1}$.

Statistics of annual wave climate at the six buoys were calculated and are summarized in Table 1, in terms of annual mean significant wave height and its standard deviation $\left(\left(H_{s}\right)_{\text {mean }} \pm\right.$ std.dev. $)$, maximum significant wave height $\left(\left(H_{s}\right)_{\max }\right)$, annual mean wave period $\left(\left(T_{e}\right)_{\text {mean }}\right)$, and annual mean and maximum wave power (i.e., $P_{\text {mean }}$ and $P_{\max }$ ). It was not surprising that $\left(H_{s}\right)_{\text {mean }}$ averaged over the period $2014-2016$ was very small, with values less than $0.5 \mathrm{~m}$ for the buoys except B4, and $\left(H_{s}\right)_{\text {mean }}$ was only about $0.1 \mathrm{~m}$ at B3 and B6. B4 displays a relatively $\left(H_{s}\right)_{\text {mean }}$, but was still very small $(0.6 \mathrm{~m})$. The largest $\left(H_{s}\right)_{\max }$ was found at B4, with value of over $4.0 \mathrm{~m}$, occurring on September 16, 2014 when Typhoon Kalmaegi (No. 1415) passed through. For Inner Dapeng Bay, represented by B1 and B2, $\left(H_{s}\right)_{\max }$ was, respectively, $2.5 \mathrm{~m}$ and $2.4 \mathrm{~m}$, and about $1.7 \mathrm{~m}$ at B5. Smallest $\left(H_{s}\right)_{\max }$ was still found at B3 and B6 (less than $1 \mathrm{~m}) .\left(T_{e}\right)_{\text {mean }}$ was relatively larger at B1, B2, B4 and 
B5 (about $4.5 \mathrm{~s})$, and smaller at B3 and B6 $(3.5 \mathrm{~s})$. The spatial distribution of wave power was similar to that of $H_{s}$ : annual mean and maximum wave power, $P_{\text {mean }}$ and $P_{\text {max }}$, were also largest at location B4 $\left(1.25 \mathrm{~kW} \mathrm{~m}^{-1}\right.$ and $88.1 \mathrm{~kW} \mathrm{~m}^{-1}$, respectively), followed by B5, B1, and B2 (respectively, 0.46 , $0.39,0.26 \mathrm{~kW} \mathrm{~m}^{-1}$ for $\left.P_{\text {mean }}\right)$, while they were still smallest at B3 and B6 $\left(0.03 \mathrm{~kW} \mathrm{~m}^{-1}\right.$ for $P_{\text {mean }}$, and 1.2 and $1.6 \mathrm{~kW} \mathrm{~m}^{-1}$ for $P_{\max }$, respectively).

Monthly and seasonal wave climate variability are of importance for wave energy resource assessment. Monthly mean and seasonal characteristics of $H_{s}$ and $T_{e}$ as well as $P$ were thus investigated for the study region, based on the buoy observations over the period 2014-2016.

Fig. 9 shows the variability in monthly values of $H_{s}, T_{e}$ and $P$ observed at the 6 buoy locations, while also displaying spatial difference in these variables between buoys. The monthly mean $H_{s}$ for 2014-2016 can be briefly divided into three groups: smallest monthly mean $H_{s}$ was found at B6 and B3, with values mostly less than $0.1 \mathrm{~m}$; monthly mean values of $H_{s}$ at B1, B2 and B5 were mostly in the range of $0.2 \mathrm{~m}-0.5 \mathrm{~m}$; largest monthly values $H_{s}$ occurred at B5, which was between $0.5 \mathrm{~m}-0.8 \mathrm{~m}$. Monthly mean values of $T_{e}$ were also smallest at B3 and B6 (mostly around $3.5 \mathrm{~s}$ ), followed by $T_{e}$ at B5 (between $4 \mathrm{~s}-5 \mathrm{~s}$ ), while monthly $T_{e}$ at B4, B2 and B1 were relatively large with values ranging between $4.5 \mathrm{~s}-6.0 \mathrm{~s}$. Correspondingly, monthly mean wave power, $P$, for the period 2014-2016 at the 6 locations can also be also divided into three groups by magnitude: largest at B4, with values ranging from about $1 \mathrm{~kW} \mathrm{~m}^{-1}$ to $3.5 \mathrm{~kW} \mathrm{~m}^{-1}$; monthly $P$ were all less than $1 \mathrm{~kW} \mathrm{~m}^{-1}$ at B1, B2 and B5; while very small values were recorded at B3 and B6, with magnitudes of all less than $0.1 \mathrm{~kW} \mathrm{~m}^{-1}$. 
Seasonal values of $H_{s}, T_{e}$ and $P$ also displayed spatial variability between the six buoy locations (see Fig. 9). At locations B3 and B6, seasonal variations in $H_{s}, T_{e}$ and $P$ were very small and limited in $0.1 \mathrm{~m}, 4 \mathrm{~s}$ and $0.1 \mathrm{~kW} \mathrm{~m}^{-1}$, respectively. Seasonal differences in $H_{s}, T_{e}$ and $P$ were evident at locations B1 and B5: seasonal values at B1 and B5 were relatively large in autumn and winter, and smaller in spring and summer months. Relative to B1 and B5, reversed seasonality was observed at B2, i.e., large values occurred in summer months with smaller values observed in winter. Largest seasonal values of $H_{s}$ (around $0.6 \mathrm{~m}$ ) were observed at B4, with relatively small variability. However, larger values of $T_{e}$ and $P$ were recorded in summer and autumn months, with smaller values in winter and spring. From the comparison between seasonal and monthly winds (Fig. 5) and waves (Fig. 9), it is not surprising that the variability in the wind climate were not coherent with those of the wave climate in the study region, since, in general, waves in the coastal area might be not generated by local winds.

In addition to the numerical values of significant wave height and energy period, their frequency of occurrence is also important for assessment of wave energy resources. The combined scatter and energy diagrams, in terms of $H_{s}, T_{e}$, and $P$, can provide convenient and comprehensive information for conveying the characteristics of wave energy resources. Fig. 10 shows the diagrams for the 6 sites, averaged at the same observational time (hourly) and all based on the data 2014-2016. In the figure, the significant wave height has been divided into intervals of one third of a meter in the range of $0-3 \mathrm{~m}$, and the energy period has been divided into intervals of $1 \mathrm{~s}$ ranging from $1 \mathrm{~s}$ to $10 \mathrm{~s}$. The colors on the diagrams show the proportion of incident energy 
expected in one year, with numerical values given by the colour bar. The black curves, $\mathrm{n}$ the values of $1 \mathrm{~kW} \mathrm{~m}^{-1}, 3 \mathrm{~kW} \mathrm{~m}^{-1}$, and $5 \mathrm{~kW} \mathrm{~m}^{-1}$, represent isolines of wave power calculated from Eq. 2. The numerical values on the diagrams in the figure represent the occurrence of a combination of $H_{s}$ and $T_{e}$ within the corresponding range, in number of hours per year.

In Inner Dapeng bay, represented by buoys B1 and B2, Fig. 10 shows that, for buoy B1, sea states in the range of $0.3-0.6 \mathrm{~m}$ for $H_{s}$ and $5-6 \mathrm{~s}$ for $T_{e}$ occurred most frequently, providing the largest contribution to the total annual wave energy (more than 30\%), and the second largest contribution (about 18\%) was from sea states with $H_{s}$ between $0.3-0.6 \mathrm{~m}$ and $T_{e}$ between $4-5 \mathrm{~s}$, which also displayed high frequency of occurrence; at B1, the frequency of occurrence of sea states with $H_{s}$ between $0 \mathrm{~m}$ and $0.3 \mathrm{~m}$ and $T_{e}$ between $4 \mathrm{~s}$ and $6 \mathrm{~s}$ was also very high, while the contribution to the total wave energy was less than $20 \%$, since their values are relatively small; moreover, sea states of $H_{s}$ between $0.3 \mathrm{~m}$ and $0.6 \mathrm{~m}$ and $T_{e}$ between $6 \mathrm{~s}$ and $7 \mathrm{~s}$ at $\mathrm{B} 1$ provided a relatively high contribution of about $15 \%$ to the wave energy, due to the relatively larger values in terms of $H_{s}$ and $T_{e}$, even though their frequency of occurrence was relatively low; for buoy B2, sea states with highest frequency of occurrence were, respectively, in the range $0.0-0.3 \mathrm{~m}$ for $H_{s}$ and $4-6 \mathrm{~s}$ for $T_{e}$, and together they contributed more than $30 \%$ of total wave energy resources, while sea states of $H_{s}$ between $0.3-0.6 \mathrm{~m}$ and $T_{e}$ between 5-6 s provided a significant contribution (more than 20\%) to the wave energy resource, followed by the contribution from sea states of $H_{s}$ and $T_{e}$, respectively, in the range of $0.3-0.6 \mathrm{~m}$ and $6-7 \mathrm{~s}$.

Concerning sea states, Fig. 10 clearly shows that for B3, located in Aoza- 
ixia Bay, within Daya bay, almost all sea states were below $0.3 \mathrm{~m}$ and in the range $6-7 \mathrm{~s}$, in terms of $H_{s}$ and $T_{e}$, respectively, and contributing more than $60 \%$ of total wave energy resources there, with the second most significant contribution coming from sea states of $H_{s}$ less than $0.3 \mathrm{~m}$ and $T_{e} 4 \mathrm{~s}$ to $5 \mathrm{~s}$. For the other buoy station in Daya Bay, B5, sea states with the highest frequency of occurrence were in the range $0.0-0.3 \mathrm{~m}$ and $4-5 \mathrm{~s}$ for $H_{s}$ and $T_{e}$, respectively, providing the largest contribution to the total annual wave energy (more than 43\%); with the second largest contribution (about $30 \%$ ) coming from sea states with $H_{s}$ and $T_{e}$ between $0-0.3 \mathrm{~m}$ and $5-6 \mathrm{~s}$, respectively; the frequency of occurrence of sea states with $H_{s}$ below $0.3 \mathrm{~m}$ were also significantly high, but their contribution to the total annual energy resources was relatively small.

For buoy B4, located off the coast of Dapeng peninsula and in the deepest location of the 6 buoys, sea states in the range of $0.3-0.9 \mathrm{~m}$ for $H_{s}$ and $4-6 \mathrm{~s}$ for $T_{e}$ provided the largest contribution to the total annual wave energy (all together more than $70 \%$ ), while sea states with larger $H_{s}$, between $0.9-1.2 \mathrm{~m}$, and $T_{e}$ between $5-6 \mathrm{~s}$ contributed about $8 \%$ of total wave energy resources. For B6, located in the narrow Shenzhen Bay, sea states in terms of $H_{s}$ and $T_{e}$, and their contributions to total wave energy, were similar to those at location B3, where water depth is also very shallow as well.

Overall, for all buoys, most sea states in terms of $H_{s}$ were below $0.6 \mathrm{~m}$, Concerning $T_{e}$, most sea state values were between $4-6 \mathrm{~s}$ for $\mathrm{B} 1-\mathrm{B} 2$, and B4-B5, while values of between 3-4s were found for B3 and B6. A basic knowledge of significant wave height values informs that values below $0.6 \mathrm{~m}$ in the ocean are quite small. It is not surprising that $H_{s}$ is small in the 
study region, since water depths are correspondingly low and the region is relatively closed off from open seas.

Wave direction plays an important role in wave energy assessment. Fig. 11 shows seasonal distributions of incoming wave direction for the 6 buoys in the study region. It is apparent from this figure that there was no obvious seasonal change in wave direction for the 6 buoys. Wave directions at these buoys locations were not in accordance with the corresponding wind directions (see Fig. 6), but they mainly reflected the wave propagating directions of propagating away from generation sources in the open region towards the coast, so that none at all was from the IV quadrant due to the coastline orientations at the buoys. Moreover, in all directions wave power was mostly less than $1 \mathrm{~kW} \mathrm{~m}^{-1}$.

In Dapeng bay, most waves came from the II quadrant: for B1, the prevailing wave direction was from the $\mathrm{SE}$, with a very minor contribution from the SSE; for B2, southerly waves prevail in all seasons except in Winter, followed by SSW, whereas SSW waves a little more occurred in winter, with a little lower occurrence (about 31\%) from the south. For Daya bay, at B3, most of the wave energy was provided by waves from the I quadrant, and the prevailing wave direction was NE, followed by ENE and NNE, which did not match the prevailing wind direction (see Fig. 6). This indicates that the waves at B3 were mostly not generated by local winds, but mostly came from the open region where the waves propagated to the coast. As for the other buoy in Daya bay, B5, most of the wave energy was contributed by easterly waves: ESE waves prevailed in winter and autumn, followed by N, whereas northerly waves occurred more in Spring and summer, followed by 
ESE; a minor contribution (less than 5\%) was due to waves from the ENE. At B4, Fig. 6 reveals that most waves came from the II quadrant, which did not match the prevailing wind directions, indicating that the waves were not generated by local winds, but from waves propagating away from generation sources in the open region. For B6 located in Shenzhen Bay, most of the waves (more than $50 \%$ on average for the all seasons) came from III, as expected, with southwesterly and WSW directions prevailing. However, it is noted that occurrence from other directions was rare, especially from the opposite direction, i.e., NE and ENE, which might be due to the fact that this is a relatively narrow area, and where the influence of reflected and refracted waves might be of more significance.

Previous studies have shown that waves transport energy supplied to them over vast distances, and dissipative effects may play only a smaller role in deep water, as opposed to the surf zone; nearshore waves are nonlinearly related to the strength, fetch, and duration of the wind [62]. Therefore, the local wave climate can be frequently affected by strong incident waves or wind fetch both inside and outside the study region.

Last but not least, we provide a brief discussion concerning the relationship between the wind energy and the wave climate for the study area. Fig. 12 displays a preliminary correlation between the wind speed/energy and the wave climate based on the local buoy measurements. Results from all buoys other than B5 (not recorded) are displayed. The upper panels of Fig. 12 show the relationship between anomalies of monthly averaged data (monthly values minus monthly climatology) of wind speed and significant wave height for the period 2014-2016. For this long-timescale (low frequency) comparison, 
the threshold correlation coefficient at the $95 \%$ and $99 \%$ significance levels is about 0.35 and 0.45 , respectively (the sample of the time series of the monthly anomalies is about 30). It can be seen from this figure that, except at B3 buoy location, all other locations display a relatively small correlation between wind strength and wave conditions. Moreover, we attempted to calculate the delay/forward correlations, but they are still insignificant (not shown). The bottom panel in Fig. 12 describes correlations between daily anomalies (daily values minus monthly climatology) of wind speed and $H_{s}$ for the period 2014-2016. The coefficients were all statistically significant (sample numbers for the time series are all greater than 550, and the threshold correlation coefficient at the $95 \%$ and $99 \%$ significance levels is less than 0.11). At Dapeng Bay, represented by buoys B1 and B2, correlations were over 0.3 for the period 2014-2016. At B3, located in Daya Bay, the correlation was very high, 0.77 . A relatively high correlation is also found at station B4 (0.60). For Shenzhen Bay (B6), the correlation coefficient is about 0.39, similar to values for Dapeng Bay. Therefore, at this daily timescale, the local wind energy significantly influences the wave climate in the study area. Thus, care must be taken before we can conclude whether the wave climate in the study region might be more affected by the local wind at daily timescale rather than for long-time statistics when non-local wave signals from outside the study region get more involved.

\section{Summary and Conclusions}

In this study, wind and wave climates for the Shenzhen coastal region are evaluated by means of buoy observational data. Buoys were first placed in 
the region by the city local government in 2014 to observe and monitor the atmospheric and hydrodynamic climate of the region. Six buoys are located in different areas of the study region, including Dapeng Bay, Daya Bay, Shenzhen Bay, and the area off the tip of the Dapeng peninsula. The waters in these areas are very shallow, ranging in depth from about $3 \mathrm{~m}-22 \mathrm{~m}$.

In terms of wind speed and direction at the buoys $(2.5 \mathrm{~m}$ above the sea surface), wind climate and potential wind energy resources were assessed in detail for the period 2014-2016. It was found that the annual mean wind speed at the buoy locations for the period 2014-2016 varied from about $3.1 \mathrm{~m} \mathrm{~s}^{-1}$ to $4.1 \mathrm{~m} \mathrm{~s}^{-1}$, with maximum wind speeds of more than $17 \mathrm{~m} \mathrm{~s}^{-1}$ occurring as a result of tropical cyclones. These winds resulted in annual mean wind powers of about $37-94 \mathrm{~W} \mathrm{~m}^{-2}$. Among the buoys, largest averaged wind speed and power were found at B4, located in the relatively open area off the southern coast of Dapeng peninsula. On average, more than $80 \%$ of wind speeds were less than $5 \mathrm{~m} \mathrm{~s}^{-1}$ in the study region. However, the wind speed was relatively large at location B4, where about $45 \%$ of wind speeds were over $5 \mathrm{~m} \mathrm{~s}^{-1}$ in winter and autumn, and $20 \%$ in summer and spring.

Seasonal variability in wind speed and power fluctuated at the different buoy locations over the 2014-2016 period. At B1 and B4, seasonal variability was relatively large in autumn and winter, and smaller in spring and summer months. However, reversed seasonality occurred at location B6, where wind and wind power were relatively large in spring and summer, and were smaller in autumn and winter. Seasonal variations were realtively small at B2 and B3 locations.

Seasonal and spatial wind direction variability differed between buoys 
B1-B4 (no wind direction data at B5 and B6). At B1, located in the northwest end of Dapeng Bay, the prevailing wind direction in winter, spring, summer and autumn was, respectively, easterly, easterly to southerly, southerly, and southerly. The prevailing wind direction was from the east in all seasons at location B2. At B3, located in Daya Bay, the largest contribution to wind energy resources was provided by the southerly winds, in all seasons, with SSE and SSW winds also providing considerable contributions. The prevailing wind direction at B4 varied seasonally, with occurrence of less than $15 \%$ from any particular direction: in winter, most winds were from the the I quadrant, followed by the II quadrant; westerly winds prevailed in spring, with southerly winds prevailing in autumn.

Wave climate and potential wave energy resources in terms of wave height, wave energy period, wave direction, and wave power were also evaluated for the period 2014-2016. The data showed that at the 6 buoy locations, $H_{s}$ was mostly less than $1 \mathrm{~m}$, and even less than $0.5 \mathrm{~m}$ at B2, B3, and B6 locations. As a result, wave power, $P$, was mostly limited to the range $10^{2}$ to $10^{3} \mathrm{~W} \mathrm{~m}^{-1}$ at B1, B4 and B5, and mostly less than $100 \mathrm{~W} \mathrm{~m}^{-1}$ at the other locations. This may be due to the facts that, first, water depth is very shallow, and, secondly, the buoys are located in bays where the sea is somewhat semienclosed, all of which are not favorable for the development of wind waves. $T_{e}$ was mostly in the range of $3-7 \mathrm{~s}$ in the study region, with values of more than $10 \mathrm{~s}$ occasionally occurring at all 6 buoys, mostly during periods of tropical cyclones.

It was not surprising that annual mean significant wave height, $\left(H_{s}\right)_{\text {mean }}$, for the period 2014-2016 was relatively small, with values of less than $1.0 \mathrm{~m}$ 
for the study region, and largest values of $\left(H_{s}\right)$ found at B4 of over $4.0 \mathrm{~m}$. In addition, most sea states in terms of $H_{s}$ were less than $0.6 \mathrm{~m}$, with $T_{e}$ between $4-6 \mathrm{~s}$ for $\mathrm{B} 1-\mathrm{B} 2$, and $\mathrm{B} 4-\mathrm{B} 5$, and $3-4 \mathrm{~s}$ for B3 and B6. The annual mean wave energy period, $\left(T_{e}\right)_{\text {mean }}$, was relatively large at B1, B2, B4 and B5 (about 4.5 s), and smaller at B3 and B6 (3.5 s). Correspondingly, the annual mean wave power was largest at B4 $\left(1.25 \mathrm{~kW} \mathrm{~m}^{-1}\right)$, and between $0.26-0.46 \mathrm{~kW} \mathrm{~m}^{-1}$ at $\mathrm{B} 1, \mathrm{~B} 2$, and $\mathrm{B} 5$, and smallest at B3 and B6, with values of only $0.03 \mathrm{~kW} \mathrm{~m}^{-1}$. Therefore, we can conclude that the potential of the wave energy resource at the buoy locations are very small.

\section{Acknowledgements}

X. Chen was funded by the National Natural Science Foundation of China (NSFC) grant 41506042. Y. Zhang was funded by the NSFC grant 51609043 and by Key Laboratory of Coastal Disaster and Defense, Ministry of Education, China, under the award 2016001. 


\section{References}

[1] China's Action Plan on Prevention and Control of Air Pollution. the State Council of the People's Republic of China; 2013.

[2] REN21. RENEWABLES 2015: Global Status Report (the Renewable Energy Policy Network for the 21st Century). REN21; 2015.

[3] Atlas of UK Marine Renewable Energy Resources. Technical Report, Report No.1432; 2008.

[4] Higgins P, Foley A. The evolution of offshore wind power in the United Kingdom. Renewable and Sustainable Energy Reviews 2014;37:599-612.

[5] Mollison D, Pontes MT. Assessing the Portuguese wave-power resource. Energy 1992;17(3):255-68.

[6] Rusu E, Guedes Soares C. Numerical modelling to estimate the spatial distribution of the wave energy in the Portuguese nearshore. Renewable Energy 2009;34(6):1501-16.

[7] Mota P, Pinto JP. Wave energy potential along the western Portuguese coast. Renewable Energy 2014;71:8-17.

[8] Waters R, Engström J, Isberg J, Leijon M. Wave climate off the Swedish west coast. Renewable Energy 2009;34(6):1600-6.

[9] Beels C, De Rouck J, Verhaeghe H, Geeraerts J, Dumon G. Wave energy on the Belgian continental shelf. In: Oceans 2007-Europe. IEEE; 2007. p. $1-6$. 
[10] Iglesias G, López M, Carballo R, Castro A, Fraguela JA, Frigaard P. Wave energy potential in Galicia (NW Spain). Renewable Energy 2009;34(11):2323-33.

[11] Iglesias G, Carballo R. Wave energy resource in the Estaca de Bares area (Spain). Renewable Energy 2010;35(7):1574-84.

[12] Iglesias G, Carballo R. Offshore and inshore wave energy assessment: Asturias (N Spain). Energy 2010;35(5):1964-72.

[13] López-Ruiz A, Bergillos RJ, Ortega-Sánchez M. The importance of wave climate forecasting on the decision-making process for nearshore wave energy exploitation. Applied Energy 2016;182:191-203.

[14] Foley AM, Kerlin C, Leahy PG. Offshore wind resource estimation using wave buoy data; 2012. p. 1114-19.

[15] Gallagher S, Tiron R, Whelan E, Gleeson E, Dias F, McGrath R. The nearshore wind and wave energy potential of Ireland: A high resolution assessment of availability and accessibility. Renewable Energy 2016;88:494-516.

[16] Clément A, McCullen P, Falcão A, Fiorentino A, Gardner F, Hammarlund K, et al. Wave energy in Europe: current status and perspectives. Renewable and Sustainable Energy Reviews 2002;6(5):405-31.

[17] Henfridsson U, Neimane V, Strand K, Kapper R, Bernhoff H, Danielsson O, et al. Wave energy potential in the Baltic Sea and the Danish part of the North Sea, with reflections on the Skagerrak. Renewable Energy 2007;32(12):2069-84. 
[18] Akpinar A, Komurcu MI. Assessment of wave energy resource of the Black sea based on 15-year numerical hindcast data. Applied Energy 2013;101:502-12.

[19] Langodan S, Viswanadhapalli Y, Dasari HP, andIbrahim Hoteit OK. A high-resolution assessment of wind and wave energy potentials in the Red Sea. Applied Energy 2016;181:244-55.

[20] Appendini CM, Urbano-Latorre CP, Figueroa B, Dagua-Paz CJ, TorresFreyermuth A, Salles P. Wave energy potential assessment in the Caribbean Low Level Jet using wave hindcast information. Applied Energy 2015;137:375-84.

[21] Hughes MG, Heap AD. National-scale wave energy resource assessment for Australia. Renewable Energy 2010;35(8):1783-91.

[22] Morim J, Cartwright N, Etemad-Shahidi A, Strauss D, Hemer M. Wave energy resource assessment along the Southeast coast of Australia on the basis of a 31-year hindcast. Applied Energy 2016;184:276-97.

[23] Cornett AM. Inventory of Canada's offshore wave energy resources. In: 25th International Conference on Offshore Mechanics and Arctic Engineering. American Society of Mechanical Engineers; 2006. p. 35362.

[24] Abbaspour M, Rahimi R. Iran atlas of offshore renewable energies. Renewable Energy 2011;36:388-398.

[25] Baba M. Wave power potential off the south-west Indian coast. Energy 1987;12(6):501-7. 
[26] Sivaramakrishnan TR. Wave power over the Indian seas during the southwest monsoon season. Energy 1992;17(6):625-7.

[27] Kumar VS, Dubhashi KK, Nair TMB, Singh J. Wave power potential at few shallow water locations around Indian coast. Current Science India 2013;104(9):1219-24.

[28] Kumar VS, Anoop TR. Wave energy resource assessment for the Indian shelf seas. Renewable Energy 2015;76:212-219.

[29] Gadad S, Deka PC. Offshore wind power resource assessment using Oceansat-2 scatterometer data at a regional scale. Applied Energy 2016;176:157-70.

[30] Oh KY, Kim JY, Lee JK, Ryu MS, Lee JS. An assessment of wind energy potential at the demonstration offshore wind farm in Korea. Energy 2012;46:555-63.

[31] Karthikeya BR, Negi PS, Srikanth N. Wind resource assessment for urban renewable energy application in Singapore. Renewable Energy $2016 ; 87: 403-14$.

[32] Watts D, Oses N, Pérez R. Assessment of wind energy potential in Chile: A project-based regional wind supply function approach. Renewable Energy 2016;96:738-55.

[33] Hagerman G. Wave Energy resource and economic Assessment for the State of Hawaii. Prepared by SEASUN Power Systems for the Department of Business, Economic Development, and Tourism, Final Report; 1992. 
[34] Stopa JE, Filipot JF, Li N, Cheung KF, Chen YL, Vega L. Wave energy resources along the Hawaiian Island chain. Renewable Energy 2013;55:305-321.

[35] Hagerman G. Southern New England wave energy resource potential. Proc. Building Energy 2001, Boston, USA; 2001.

[36] Beyene A, Wilson JH. Comparison of wave energy flux for northern, central, and southern coast of California based on long-term statistical wave data. Energy 2006;31(12):1856-69.

[37] Wilson JH, Beyene A. California wave energy resource evaluation. Journal of Coastal Research 2007;p. 679-90.

[38] Defne Z, Haas KA, Fritz HM. Wave power potential along the Atlantic coast of the southeastern USA. Renewable Energy 2009;34(10):2197205.

[39] Lenee-Bluhm P, Paasch R, Özkan-Haller H. Characterizing the wave energy resource of the US Pacific Northwest. Renewable Energy 2011;36(8):2106-19.

[40] Cornett AM, et al. A global wave energy resource assessment. In: Proceedings of the Eighteenth International Offshore and Polar Engineering Conference, Vancouver, Canada; 2008. p. 1-9.

[41] Mork G, Barstow S, Kabuth A, Pontes MT. Assessing the global wave energy potential. In: ASME 2010 29th International Conference on Ocean, Offshore and Arctic Engineering. American Society of Mechanical Engineers; 2010. p. 447-54. 
[42] Gunn K, Stock-Williams C. Quantifying the global wave power resource. Renewable Energy 2012;44:296-304.

[43] Arinaga RA, Cheung KF. Atlas of global wave energy from 10 years of reanalysis and hindcast data. Renewable Energy 2012;39:49-64.

[44] Reguero BG, Losada IJ, Méndez FJ. A global wave power resource and its seasonal, interannual and long-term variability. Applied Energy $2015 ; 148: 366-80$.

[45] Zhou W, Yang H, Fang Z. Wind power potential and characteristic analysis of the Pearl River Delta region, China. Renewable Energy $; 31(6)$.

[46] Li J, Gao H, Shi P, Shi J, Ma L, Qin H. China wind power report 2007; 2007.

[47] Zhang D, Li W, Lin Y. Wave energy in China: Current status and perspectives. Renewable energy 2009;34(10):2089-92.

[48] Xia C, Song Z. Wind energy in China: current scenario and future perspectives. Renewable and Sustainable Energy Reviews 2009;13:196674 .

[49] Han J, Arthur PJM, Lu Y, Zhang L. Onshore wind power development in China: challenges behind a successful story. Energy Policy $2009 ; 37: 2941-51$.

[50] Rajgor G. China gets serious on offshore wind. Renewable Energy Focus 2010;September/October. 
[51] Wang S, Yuan P, Li D, Jiao Y. An overview of ocean renewable energy in China. Renewable and Sustainable Energy Reviews 2011;15(1):91-111.

[52] Zheng C, Zhuang H, Li X, Li X. Wind energy and wave energy resources assessment in the East China Sea and South China Sea. Science China Technological Sciences 2012;55(1):163-73.

[53] Jiang D, Zhuang D, Huang Y, Wang J, Fu J. Evaluating the spatiotemporal variation of China's offshore wind resources based on remotely sensed wind field data. Renewable and Sustainable Energy Reviews 2013;24:142-148.

[54] Wu S, Liu C, Chen X. Offshore wave energy resource assessment in the East China Sea. Renewable Energy 2015;76:628-36.

[55] Li G. Feasibility of large scale offshore wind power for Hong Kong ąła preliminary study. Renewable Energy 2000;21(3):387-402.

[56] Lu L, Yang H, Burnett J. Investigation on wind power potential on Hong Kong islands ąłan analysis of wind power and wind turbine characteristics. Renewable Energy 2002;27(1):1-12.

[57] Gao X, Yang H, Lu L. Study on offshore wind power potential and wind farm optimization in Hong Kong. Energy 2014;130:519-31.

[58] Shu ZR, Li QS, Chan PW. Investigation of offshore wind energy potential in Hong Kong based on Weibull distribution function. Applied Energy 2015;156:362-73. 
[59] Roger B. Wave energy forecasting accuracy as a function of forecast time horizon; 2009.

[60] Committee CSA. Classification of tropical cyclones (GB/T19201-2006); 2006.

[61] Ying M, Zhang W, Yu H, Lu X, Feng J, Fan Y, et al. An Overview of the China Meteorological Administration Tropical Cyclone Database. Journal of Atmospheric and Oceanic Technology 2013;(2013).

[62] Zhang Y, Kennedy AB, Tomiczek T, Donahue AS, Westerink JJ. Validation of Boussinesq-Green-Naghdi Modelling for Surf Zone Hydrodynamics. Ocean Engineering 2016;111:299-309. 
Table 1: List of measurement buoys in the Shenzhen coastal region with water depth and some fundamental mean wind and wave characteristics. The collected buoy data covered from April 2014 to the end of 2016, with data gap that can be seen in Fig. 2. Main wind and wave characteristics were statistically calculated, including wind speed, $V\left(\mathrm{~m} \mathrm{~s}^{-1}\right)$; wind power, $W\left(\mathrm{~W} \mathrm{~m}^{-2}\right)$; significant wave height, $H_{s}(\mathrm{~m})$; wave energy period, $T_{e}(\mathrm{~s})$; wave power, $P\left(\mathrm{~kW} \mathrm{~m}^{-1}\right)$.

\begin{tabular}{cccccccccccc}
\hline Buoy & Depth $(\mathrm{m})$ & $\begin{array}{c}V_{\text {mean }} \\
\text { std.dev. }\end{array}$ & \multicolumn{1}{c}{$V_{\max }$} & $W_{\operatorname{mean}}$ & $\begin{array}{r}W_{\max }\left(H_{s}\right)_{\operatorname{mean}}\left(H_{s}\right)_{\max }\left(T_{e}\right)_{\operatorname{mean}} P_{\operatorname{mean}} P_{\max } \\
\text { std.dev. }\end{array}$ \\
\hline B1 & 11 & $3.1 \pm 2.3$ & 17.5 & 58 & 3282 & $0.34 \pm 0.18$ & 2.5 & 4.7 & 0.39 & 22.5 \\
B2 & 11 & $3.1 \pm 1.7$ & 17.6 & 37 & 3339 & $0.25 \pm 0.17$ & 2.4 & 4.7 & 0.26 & 28.0 \\
B3 & 5 & $3.4 \pm 2.0$ & 15.6 & 52 & 2325 & $0.11 \pm 0.05$ & 0.8 & 3.5 & 0.03 & 1.2 \\
B4 & 22 & $4.1 \pm 2.5$ & 17.1 & 94 & 3063 & $0.62 \pm 0.30$ & 4.3 & 4.5 & 1.25 & 88.1 \\
B5 & 12 & $/$ & $/$ & $/$ & $/$ & $0.38 \pm 0.23$ & 1.7 & 4.3 & 0.46 & 8.7 \\
B6 & 3 & $3.6 \pm 1.8$ & 15.7 & 51 & 2347 & $0.13 \pm 0.05$ & 0.9 & 3.5 & 0.03 & 1.6 \\
\hline
\end{tabular}




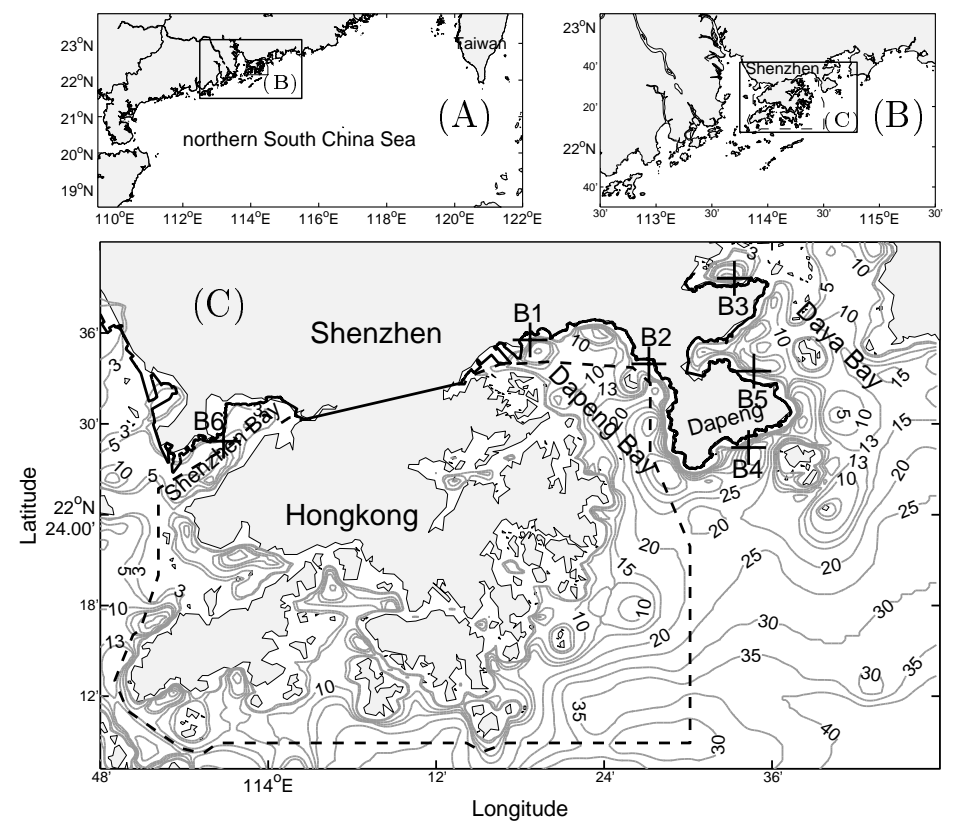

Figure 1: (C): Bathymetry contours (m) for the study area together with locations of the six wind and wave measurement buoys (B1-B6) in the coastal Shenzhen region (bottom/main panel). The study area is situated in the northern South China Sea (top panels). The broken line represents the boundary of Hong Kong waters. 


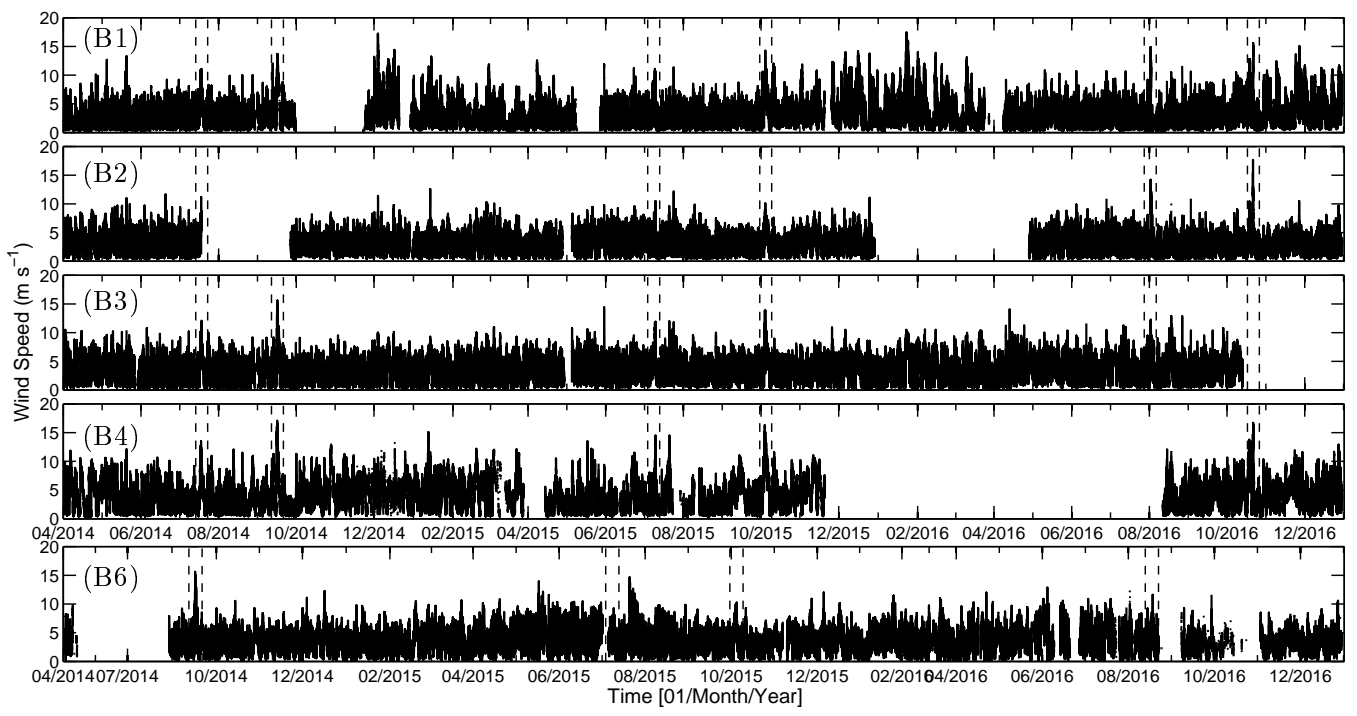

Figure 2: Time series of wind speed $\left(\mathrm{m} \mathrm{s}^{-1}\right)$ at the buoy locations (B1-B4 and B6) shown in Fig. 1 for the period 2014-2016. Dashed lines show the time periods of the tropical cyclones (see Fig. 4) passing through the study region. Wind data were missed at B5 buoy. 


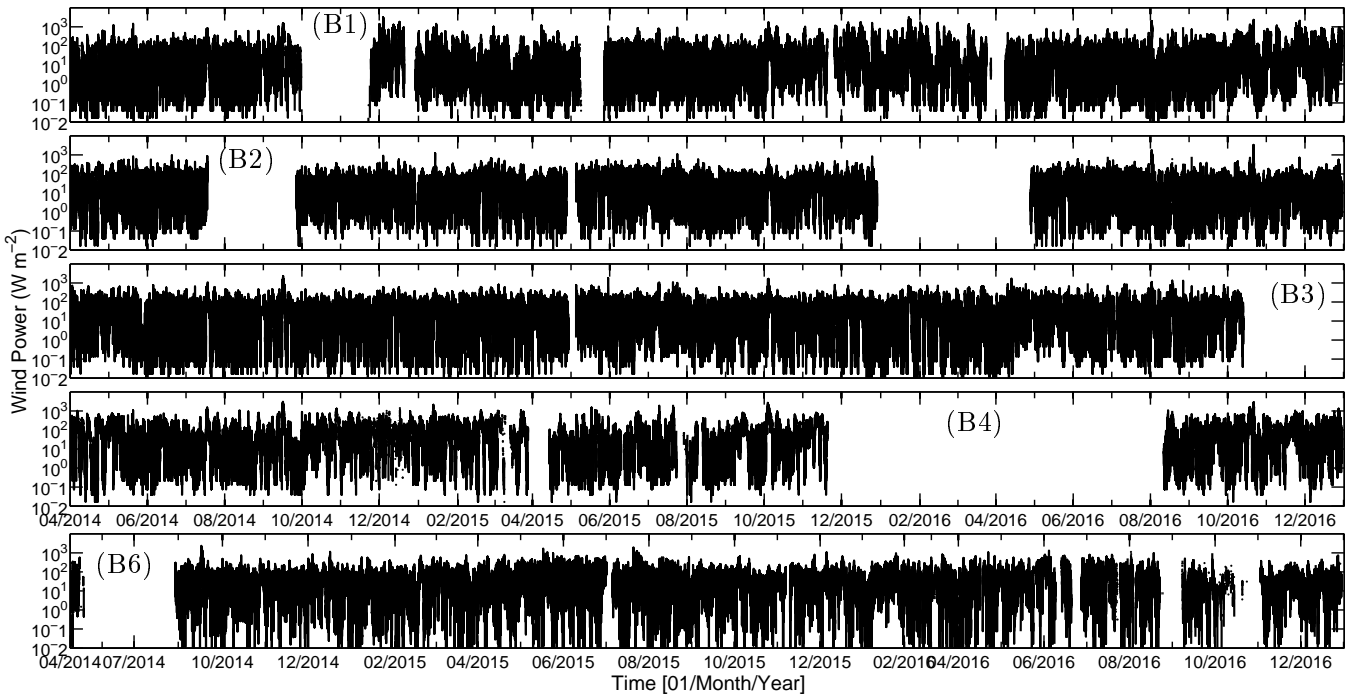

Figure 3: Time series of wind power $\left(\mathrm{W} \mathrm{m}^{-2}\right)$ at locations $\mathrm{B} 1-\mathrm{B} 4$ and $\mathrm{B} 6$ shown in Fig. 1 for the period 2014-2016. 


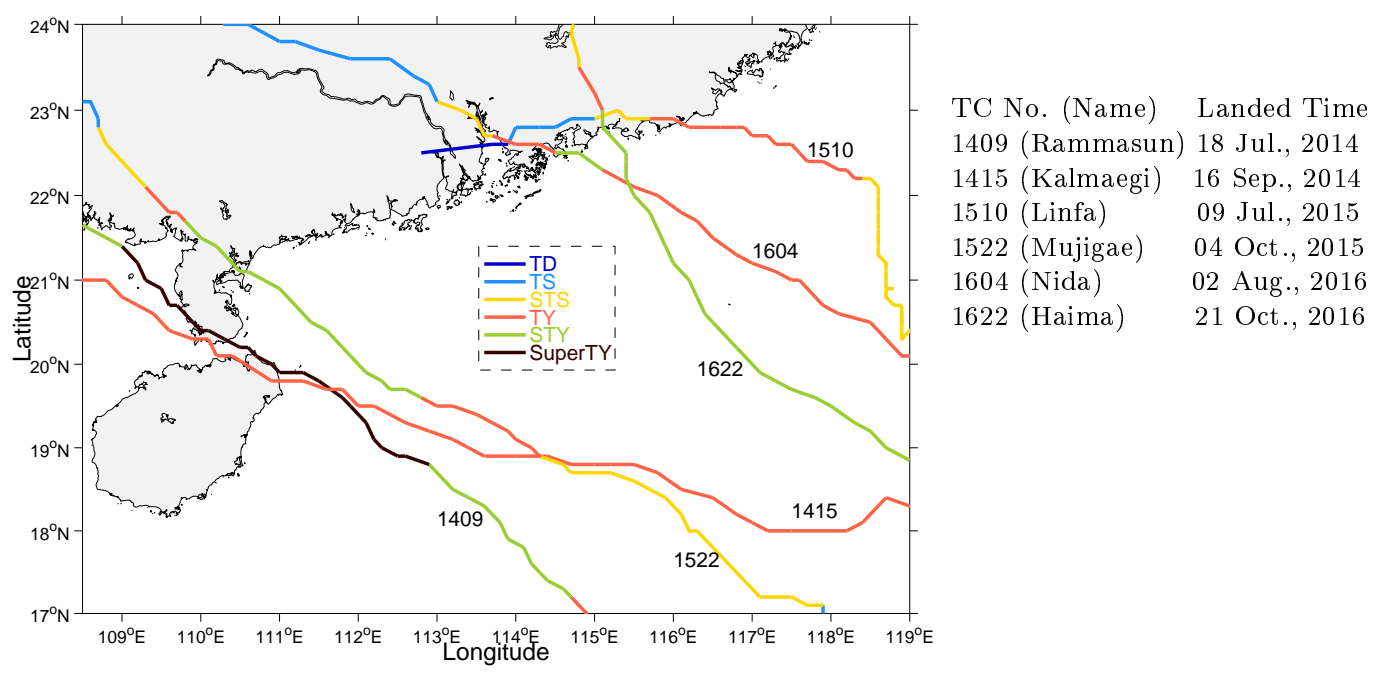

Figure 4: Left: Paths of tropical cyclones (TCs) passing through the northern South China Sea for the period 2014-2016. Right: The TC No. (Name) and landed time. Data source: http://tcdata.typhoon.gov.cn/zjljsjj_sm.html [61]. The classifications of the TCs in China are as follows: Tropical Depression (TD; $10.8-17.1 \mathrm{~m} \mathrm{~s}^{-1}$ ); Tropical Storm (TS; $17.2-24.4 \mathrm{~m} \mathrm{~s}^{-1}$ ); Severe Tropical Storm (STS; $24.5-32.6 \mathrm{~m} \mathrm{~s}^{-1}$ ); TYphoon (TY; 32.7-41.4 $\mathrm{m} \mathrm{s}^{-1}$ ); Severe TYphoon (STY; 41.5-50.9 $\mathrm{m} \mathrm{s}^{-1}$ ); and Super TYphoon (SuperTY; $\geqslant 51.0 \mathrm{~m} \mathrm{~s}^{-1}$ )
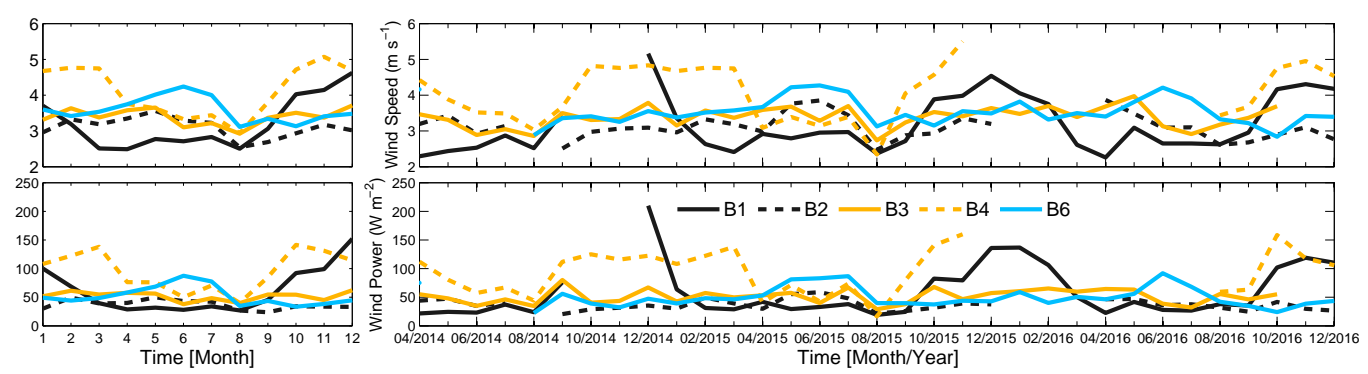

Figure 5: Seasonal (left) and monthly (right) mean wind speed $\left(\mathrm{m} \mathrm{s}^{-1}\right)$ and wind power $\left(\mathrm{W} \mathrm{m}^{-2}\right.$ ) for the buoys B1-B4 and B6 shown in Fig. 1. 

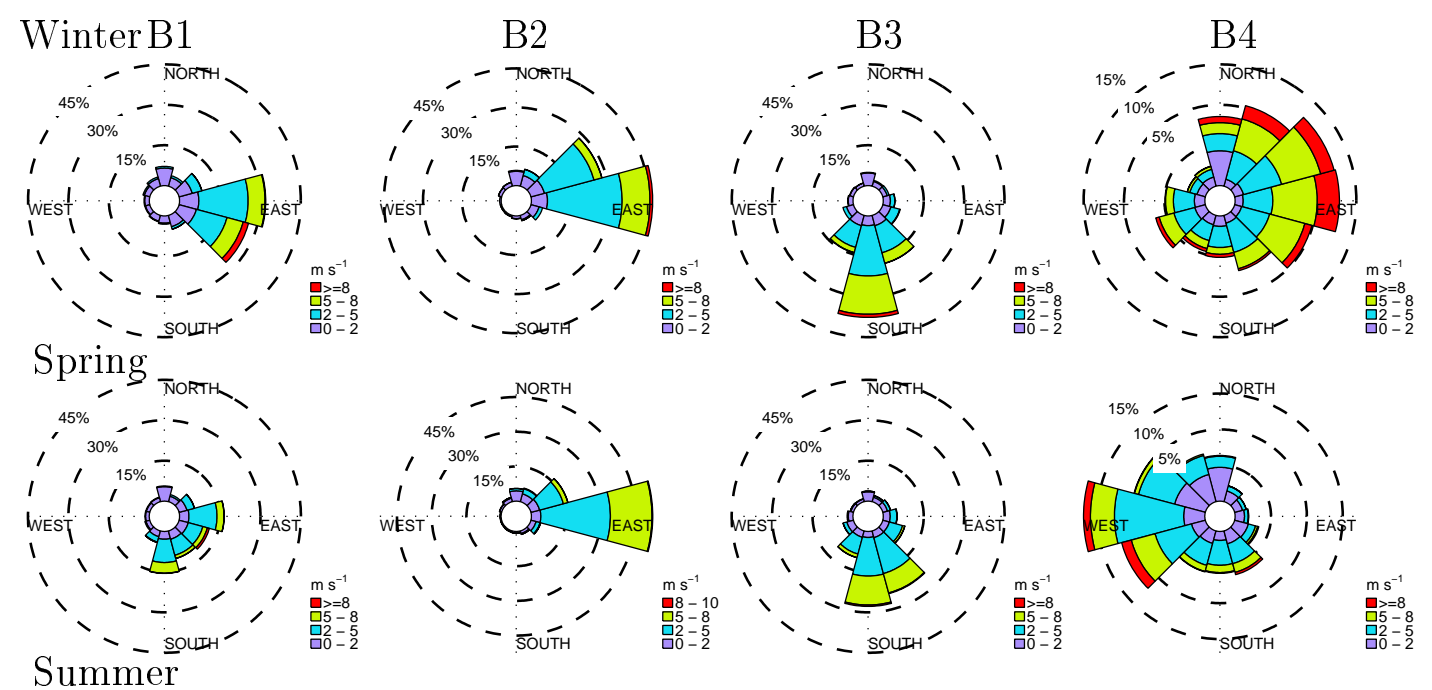

Summer
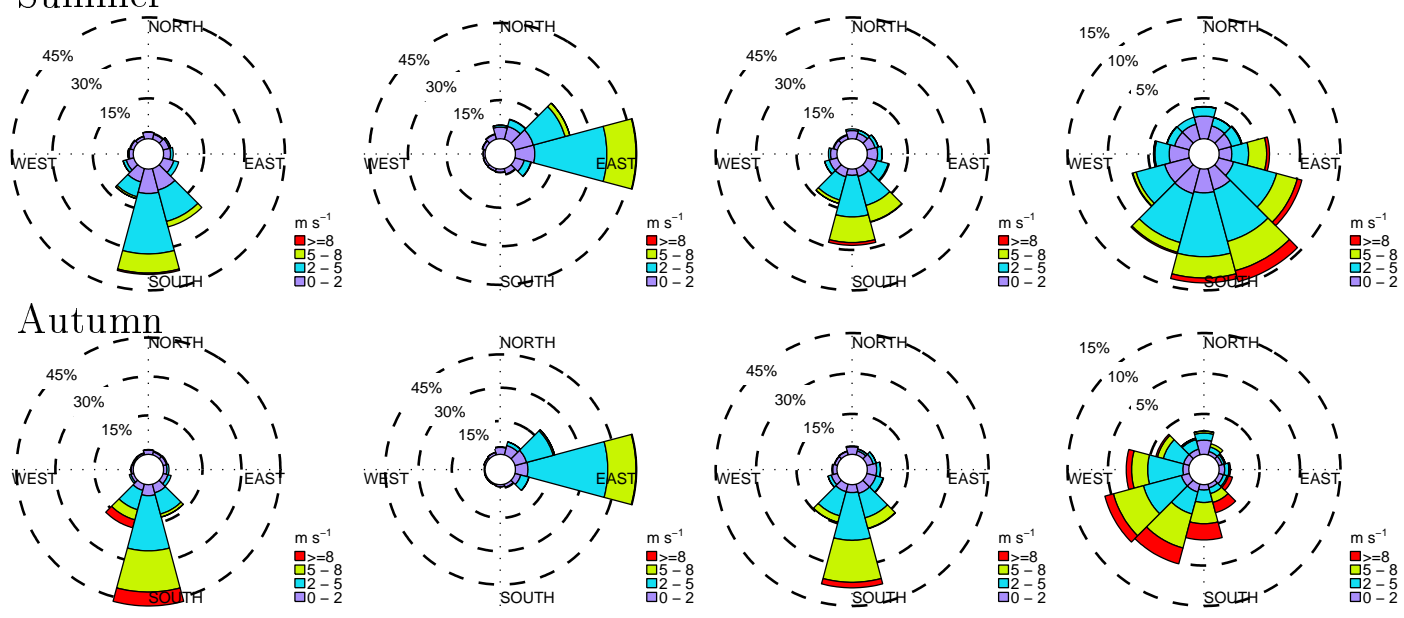

Figure 6: Seasonal wind speed and direction roses based on the measurement from buoys B1-B4 for the period 2014-2016. Wind direction data were missed at B5 and B6 locations. 

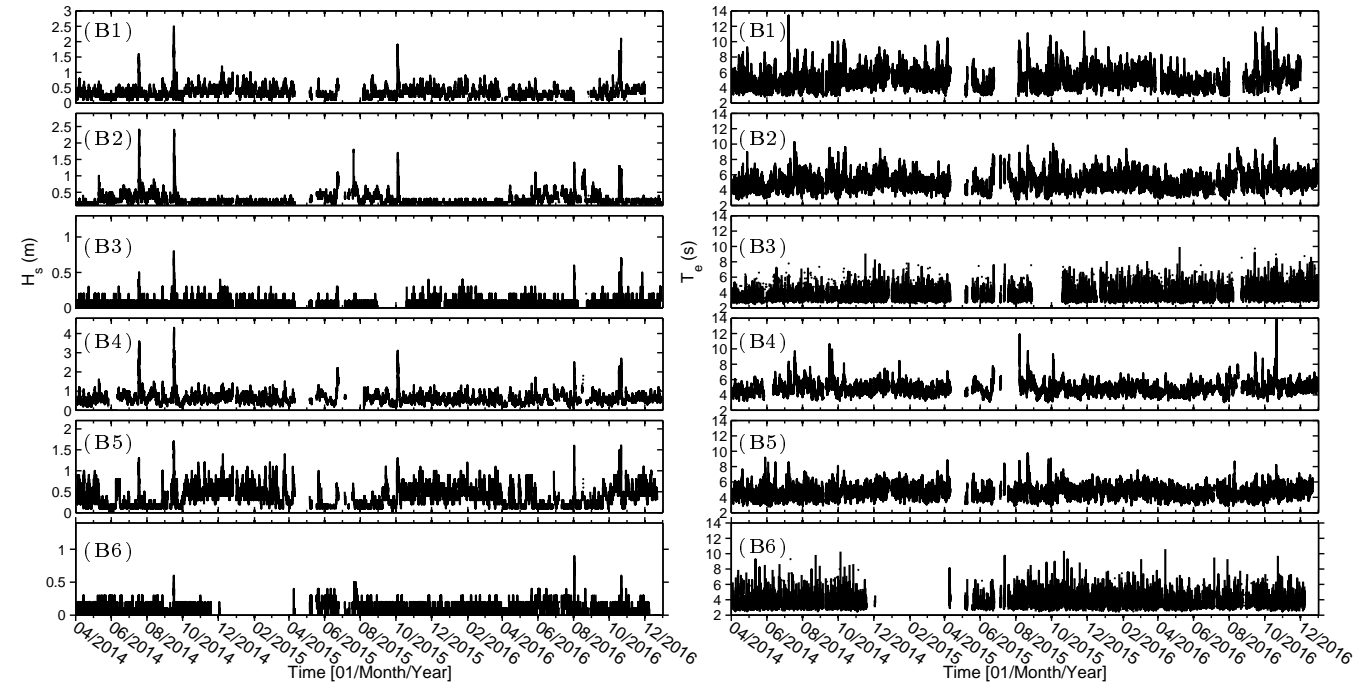

Figure 7: Time series of significant wave heights $\left(H_{s}\right.$ in $\left.\mathrm{m}\right)$ and wave energy periods $\left(T_{e}\right.$ in s) at the six buoy locations (B1-B6) for the period 2014-2016.

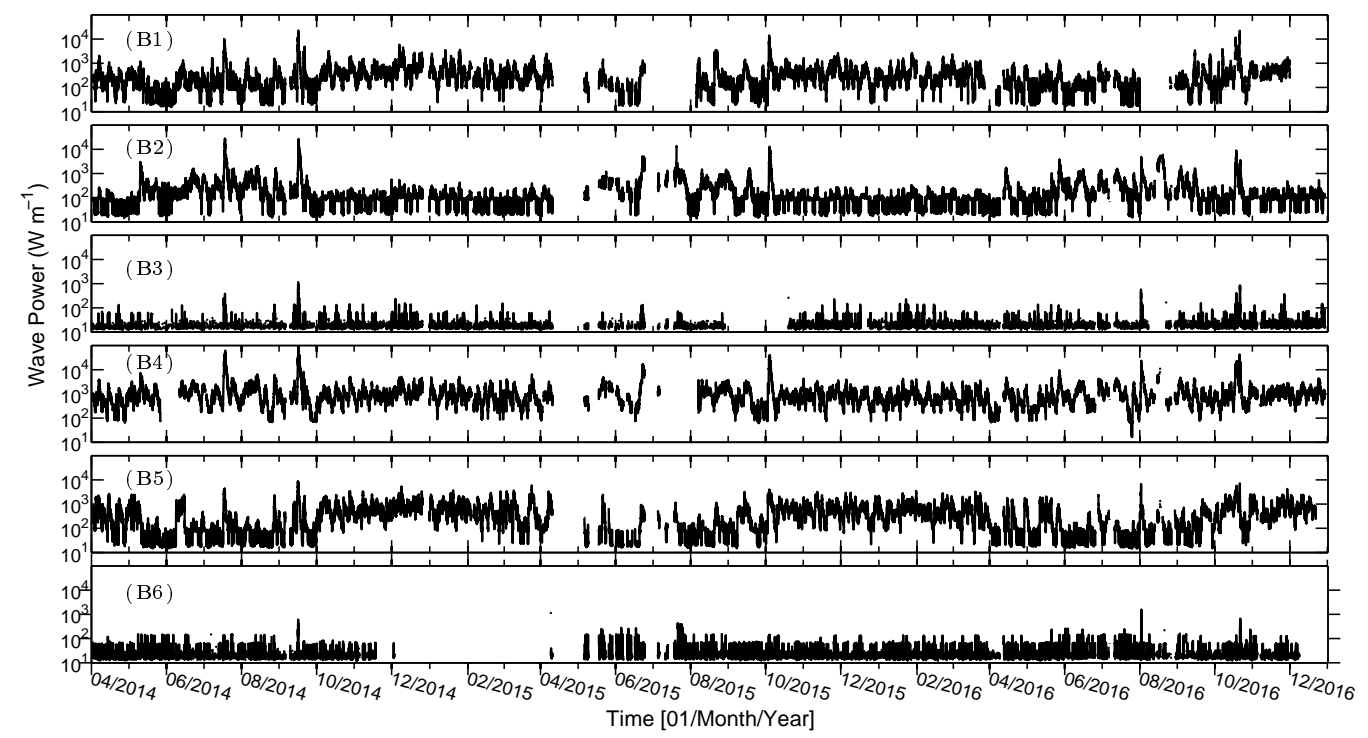

Figure 8: Time series of wave power $\left(\mathrm{W} \mathrm{m}^{-1}\right), P$, at buoy locations of $\mathrm{B} 1-\mathrm{B} 6$ shown in Fig. 1 for the period 2014-2016. 

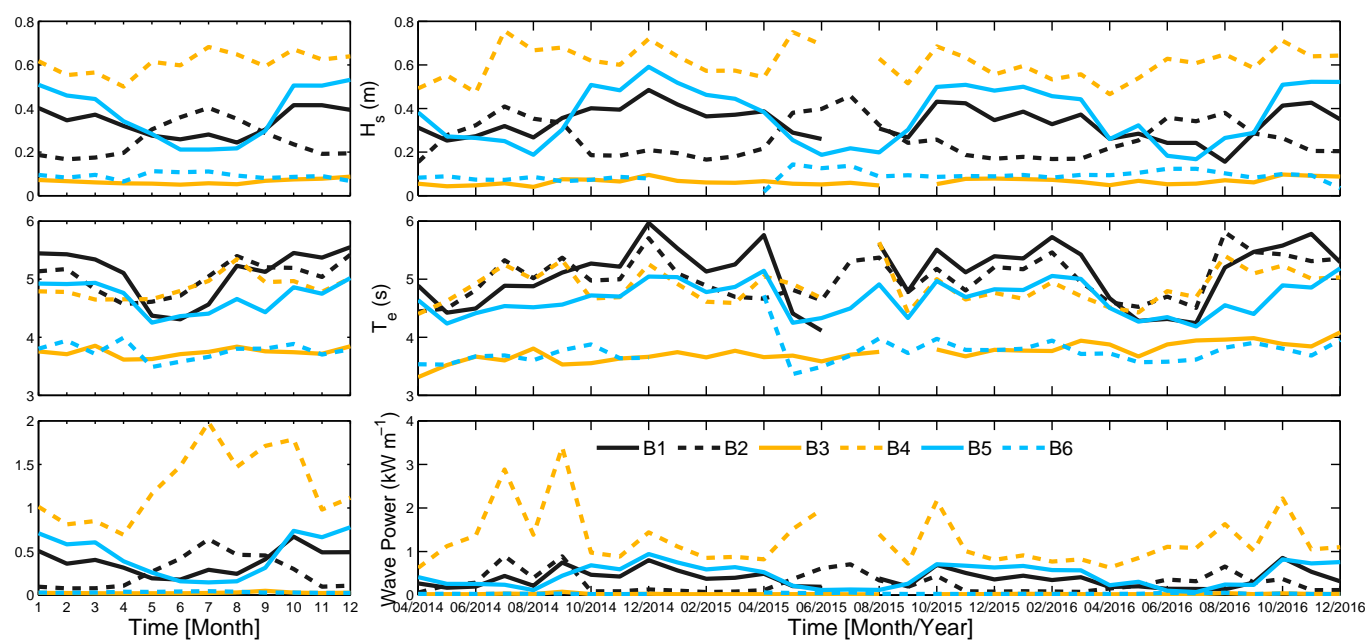

Figure 9: Seasonal (left) and monthly (right) mean significant wave height $\left(H_{s}\right)$, energy period $\left(T_{e}\right)$, and wave power $(P)$, for the six buoys $(\mathrm{B} 1-\mathrm{B} 6)$ shown in Fig. 1 for the period $2014-2016$.
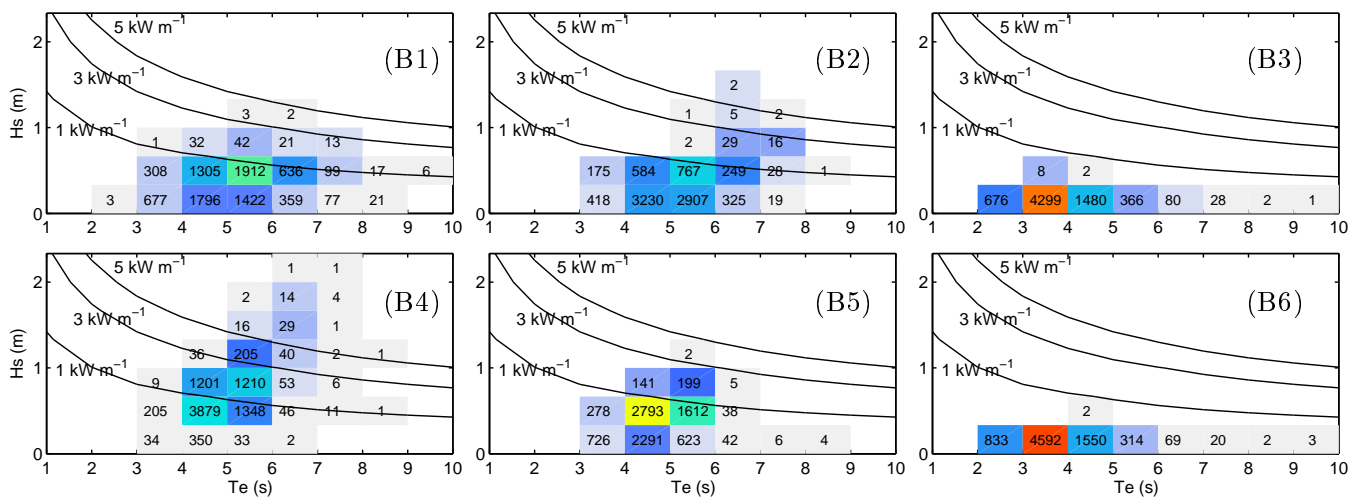

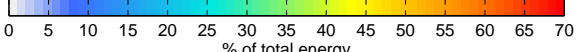

Figure 10: Bivariate distributions of occurrence and energy in terms of significant wave height $\left(H_{s}\right)$, and energy period $\left(T_{e}\right)$ averaged for the period $2014-2016$ for at the six stations displayed in Fig. 1. The color scale, as a percentage, represents the contribution of the sea state to the total energy, while the black numbers indicates the occurrence of sea states in number of hours in one year. 


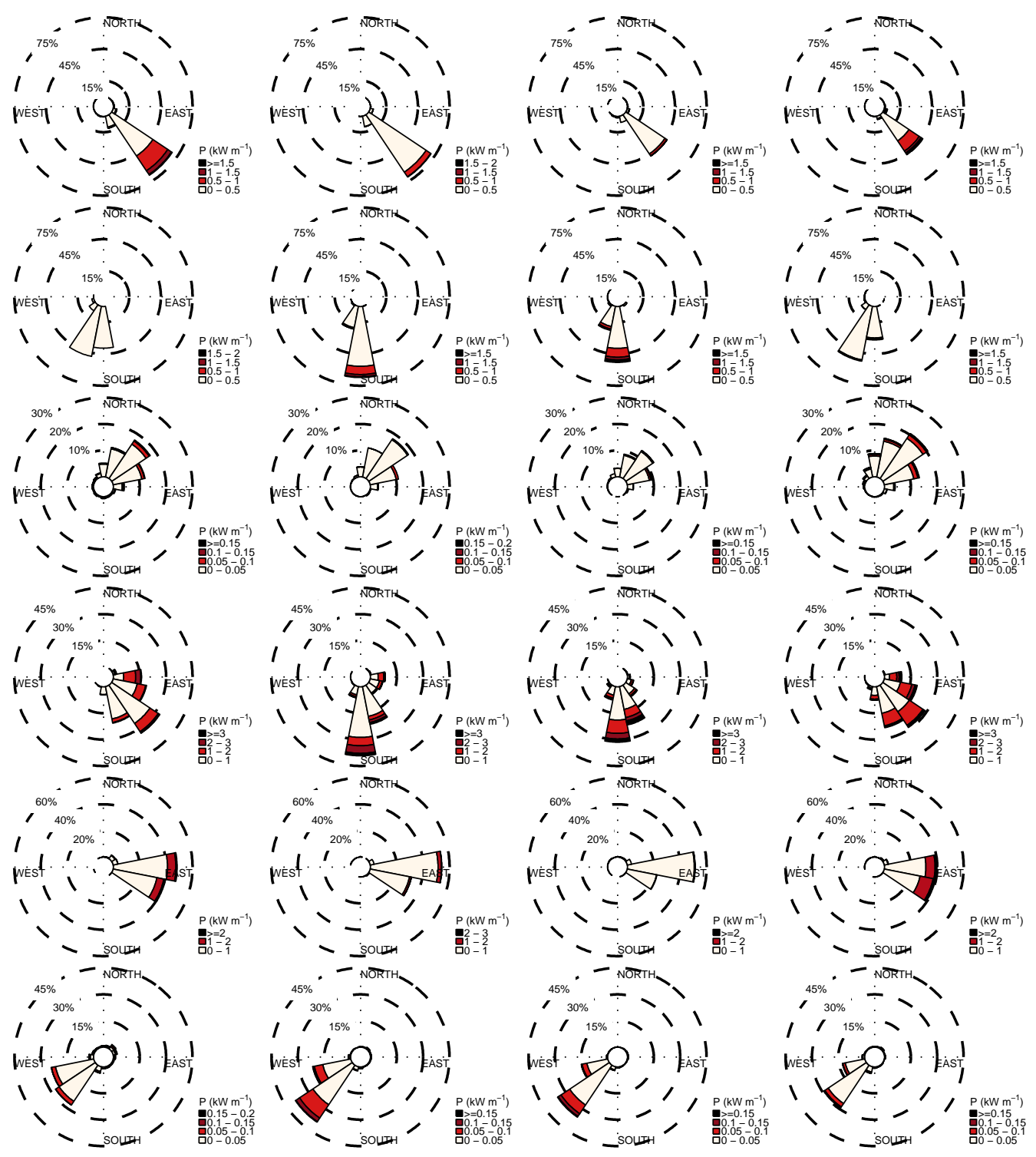

Figure 11: Seasonal wave power and direction roses based on the measurement from the buoys B1-B6 for the period 2014-2016. 


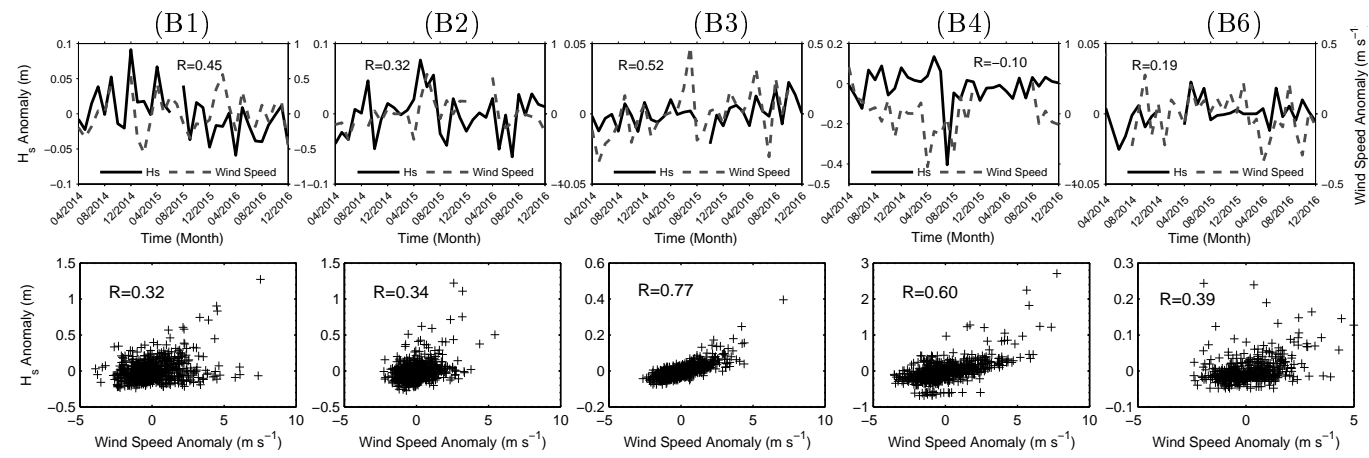

Figure 12: Top panel: the relationship between anomalies of monthly averaged data (monthly values minus monthly climatology) of wind speed and significant wave height, $H_{s}$, at buoys B1-B4 and B6 for the period 2014-2016. Bottom panel: the relationship between anomalies of daily averaged (daily values minus monthly climatology) of wind speed and Hs at the buoys B1-B4 and B6 (as above). R represents correlation coefficient. 